\title{
Ramis Barceló, Rafael. El nacimiento de la Filosofía del derecho. De la Philosophia iuris a la Rechtsphilosophie. Madrid: Dykinson, 2021.
}

\author{
Jesús Muñoz Almazán \\ Departamento de Ciencia Política, Derecho Constitucional y Filosofía del Derecho \\ Universitat de Barcelona
}

Fecha de recepción 01/05/2021 I De publicación: 24/06/2021

La colección de Historia del Derecho de la editorial Dykinson suma entre sus volúmenes una obra que es, lo decimos de entrada, de enorme importancia para la historiografía del pensamiento jurídico. Rafael Ramis Barceló, investigador de fecunda trayectoria académica, se pregunta cuándo surge la noción de «filosofía del derecho» y cuál es su travesía histórica, ¿por qué la filosofía del derecho hoy se imparte en la Facultad de los juristas cuando las filosofías de genitivo (del lenguaje, de la ciencia, de la economía) son cosa de la Facultad de los filósofos? Para encontrar respuesta, Ramis ha realizado una profunda investigación entre libros de filósofos y juristas olvidados del siglo XVI y XVII, períodos hasta ahora inexplorados por los historiadores de la filosofía del derecho.

La escasa historiografía producida sobre la noción de «filosofía del derecho» (a pesar de ser mayoritariamente alemana, destaca el trabajo de Del Vecchio) asumió que su procedencia era germánica, que se acuñó contra las doctrinas del derecho natural, en el seno del debate decimonónico entre Gustav Hugo y Friedrich Hegel y sus epígonos; sí se reconocía anecdóticamente que el sintagma philosophia iuris se encontraba ya en Leibniz y antes en Chopius. En España, Felipe González Vicén heredó la tesis de Del Vecchio y la escoró hacia el positivismo jurídico: entendía que toda filosofía del derecho era de signo positivista y por lo tanto contra toda metafísica y derecho natural; olvidaba pues los precedentes de la philosophia iuris que no tenían otro objeto de estudio más que el derecho natural.

Ramis nos confiesa que durante su etapa estudiantil los trabajos de González Vicén saciaron la prematura pregunta por la noción de «filosofía del derecho»; sin embargo, por las deudas que contrae a lo largo del libro con Francisco Carpintero, podemos sospechar que la crítica de éste hacia las tesis de González Vicén le ayudó sobremanera a salir de los límites de la historiografía germánica. Carpintero apuntaba en su crítica que se había producido un injusto olvido de los iusnaturalistas modernos (Grocio, Pufendorf, Thomasius) y tardíos (Baumgarten, Achenwall, Kant y seguidores); que aún en el siglo XIX los 
conceptos Naturrecht y Rechtsphilosophie seguían siendo sinónimos. La crítica de Carpintero era eficaz pero no resolvía del todo la cuestión, porque seguían ausentes los autores del XVI y parte del XVII. Tampoco eran completos los estudios historiográficos de Pfordten y Klippel sobre la noción de filosofía del derecho, aunque sin duda sirvieron de base para iniciar la investigación de Ramis.

La laguna se encontraba en los siglos XVI y XVII, el periodo de entre aguas marginado por la historiografía filosófica. Los pensadores que figuran en estos lares de la historia son incómodos de encajar si uno sólo toma como referencia los movimientos intelectuales inmediatos, sea Erasmo o Descartes. En el Quinientos culminan las tradiciones avenidas de la Baja Edad Media y, si no se conocen las improntas de Accursio, Tomás de Aquino o Scoto, quedan relegados a la anécdota muchos autores que no hablaron con motivos renacentistas o protoracionalistas y sin embargo fueron cruciales para el devenir de la filosofía moderna. Ramis conoce bien este flujo bajomedieval que impregna los albores de la modernidad y por eso comienza su travesía histórica con la vera philosophia de los juristas del derecho romano.

Una tradición de romanistas siguió al pie de la letra las palabras de Ulpiano, cuando define a los juristas como los que van en busca de la verdadera filosofía y no de la falsa (veram philosophiam, non simulata). Estos juristas comenzaron a considerar el campo del derecho con autonomía respecto a la filosofía e incluso con cierta superioridad, pues el derecho - lo decía Ulpiano- era la verdadera filosofía, la filosofía práctica, frente a la abstracta dialéctica de los filósofos. Surgió entonces la noción de philosophia legalis para denominar a esta autónoma filosofía de los juristas; y así fue hasta 1550.

Es entonces, a mediados del Quinientos, cuando se produce una crisis epistemológica en el derecho que obligó a los juristas a dejar a un lado el orgullo de su oficio y a valorar la filosofía como una fuente de conceptos útiles para armar de rigor la metodología jurídica. El sintagma philosophia legalis desplazó su significado y pasó a referir aquel derecho que era dependiente de la filosofía. Ya en el siglo XVII esta noción «indicó con más claridad la búsqueda de unos primeros principios del derecho, aunque progresivamente fue sustituyéndose por el concepto de philosophia iuris» (p. 48). A partir de 1650, la philosophia iuris sustituyó a la romanista philosophia legalis. Este desplazamiento de significados queda detallado en los capítulos dos y tres con una exposición erudita de autores olvidados.

En el cuarto capítulo se nos presenta el periodo de 1650-1675, cuando se produce el éxito de la noción philosophia iuris y se expande el uso del sintagma en los títulos de las obras jurídicas. Nos dice el autor 
que estos escritos, en líneas generales, están marcados por un aristotelismo luterano que seguía bebiendo del derecho romano. Es el caso de Chopius y su Philosophia juris vera (1650), destinada a fundamentar los principios del derecho privado mediante la filosofía aristotélica; se trata de un primer eslabón importante para el devenir de la noción. El amplio rastreo de libros que muestran estas páginas revela que la noción se asienta especialmente en círculos germánicos y protestantes y así lo atestiguan los comentarios que Ramis ofrece de Hahn, Conring, Beckmann, Rachel, Unverfäth y Leibniz, si bien éste último merece una nota aparte en el libro por su especial originalidad filosófica.

El curso de la philosophia iuris se detiene en el quinto capítulo para presentar otra noción que fue paralela y gozó de fortuna hasta el siglo XVIII: la philosophia iuris consultorum. El autor nos advierte que no debe confundirse con la tradición antes presentada y que debe considerarse de forma independiente. Se trata de juristas, germánicos en su mayoría, que se mantuvieron firmes en la autonomía del derecho frente a la filosofía; entre ellos destaca Slevogt. Quien quisiera emplearse como jurista, entonces, no debía estudiar otra cosa que a los jurisconsultos y, en todo caso, la referencia ideológica inmediata de estos juristas clásicos, esto es, el estoicismo. Es una corriente que reacciona a los excesos filosóficos de los juristas que acudían a Aristóteles. Ramis volverá a esta corriente en el capítulo octavo para hacer una panorámica de su desarrollo a lo largo del siglo XVIII y de su resolución historicista.

La tercera tradición que baila con las anteriores es la del ius naturale et gentium, mejor conocida por las personalidades de Pufendorf y Thomasius. La corriente aristotélica que tomaba la expresión philosophia iuris, en tanto que aristotélica, se oponía a las modernas filosofías constructivistas e individualistas de Vázquez de Menchaca o Hobbes. Estas corrientes racionalistas insuflaron los autores del ius naturale et gentium, dando origen a lo que Ramis trata en el capítulo sexto: la philosophia iuris racionalista. El joven Thomasius escribió una Philosophia iuris ostensa (1682) que, como bien muestra el título, hacía eco de la noción philosophia iuris para exponer los principios filosóficos del derecho y la sociedad. Sin embargo, el sintagma desaparece en el Thomasius maduro con su Paulo Plenior, Historia Juris Naturalis (1718), para preferir el nombre de ius naturale et gentium. Ramis ve en Thomasius el punto de encuentro entre la noción philosophia iuris y la doctrina del derecho natural racionalista, encuentro que marca la suerte del sintagma en los inicios del siglo XVIII.

Es en el capítulo séptimo cuando se nos despliega esta suerte racionalista de la philosophia iuris. La influencia de Pufendorf y Thomasius fue tan grande que se acabó asociando la philosophia iuris a la doctrina del ius naturale et gentium. Nombres como Ferber, Hartung, Zollicoffer, Künhold, Burkhard 
Wolf o Reftelius contribuyeron enormemente a que perviviera esta asociación al menos hasta 1730, cuando se detiene la publicación de textos titulados con este sintagma, no así el uso de la noción.

El periodo 1730-1780 es el dominado por el ius naturale et gentium de Pufendorf, Thomasius y Wolff. Durante estas décadas se asiste a las primeras traducciones de la noción philosophia iuris a lenguas vernáculas y al surgimiento de otras expresiones alternativas, como philosophia justi, ius philosophicum o theoria iuris. Estos procesos quedan registrados en el capítulo noveno, donde también se hace especial mención a Kant, cuya influencia define las corrientes del pensamiento jurídico del siglo XIX, no sólo por su originalidad conceptual, también porque con él el derecho positivo y el derecho natural se definen separadamente. A partir de este momento la ciencia del derecho se bifurca: por un lado, los que atienden al metafísico derecho natural, los de la natürliche Rechtslehre; por otro lado, como reacción a los excesos filosóficos de los iusnaturalistas, los que se centran en el derecho positivo, los de la Philosophie des positiven Rechts.

La philosophia iuris logró pervivir en el siglo XIX mediante el transvase terminológico germano. Aquel iusnaturalismo de signo racionalista se mantuvo bajo los nombres de Philosophie des Rechts, Rechtsphilosophie, Naturrecht y Rechtslehre, éste último más asociado a los seguidores de Kant. Estos últimos coletazos de la filosofía del derecho más endeudada con la tradición filosófica se precisan en el capítulo décimo, que hace llegar esta travesía histórica hasta Hegel como último heredero de esta corriente. Del XIX sale victoriosa la Philosophie des positiven Rechts: el positivismo jurídico se alza como única filosofía del derecho; se queda, pues, en la Facultad de Derecho la filosofía que renuncia a salir de los términos estrictamente jurídicos.

Nuestro presente sigue siendo deudor de aquella contienda, como se nos dice en el epílogo, que pasa revista del presente de la filosofía del derecho y las líneas que se abren al mañana. Finalmente, las conclusiones recogen todo lo andado y las principales aportaciones que el libro ofrece a la historiografía del pensamiento jurídico.

El método de investigación de Ramis es el de la historia conceptual: analizar el uso de términos, situados en su contexto intelectual y social y seguir su desarrollo histórico. Toma las obras jurídicas que hacen referencia a la philosophia iuris y derivados en el título o en alguno de los capítulos y las disecciona atendiendo a la relación que toma la filosofía respecto al derecho y a la orientación filosófica y religiosa de la obra (si es apegada o no a Aristóteles, si proviene de círculos católicos o protestantes, si se reconoce 
alguna deuda con algún autor o tradición, etc.). Para estos comentarios críticos, Ramis utiliza la forma de la reseña: luego de dar unas breves notas biográficas de los autores, despliega su afinada crítica textual con ayuda de extractos de los libros reseñados en su lengua original (algo que agradecerá el avezado en el latín y el alemán, pero que será una barrera para quien no domine estas lenguas). Estas reseñas, que justifican la línea historiográfica que dibuja Ramis y que demuestran el buen oficio de historiador de las ideas que hay tras El nacimiento de la Filosofía del Derecho, permiten además insinuar más de una línea de investigación para el mañana: queda aún mucha tela que cortar en los nombres aquí recogidos.

Es una tarea muy difícil definir el contorno de esos diálogos diacrónicos que llamamos tradiciones, más cuando los actores del traditus de ideas son apenas conocidos, más aún cuando nuestra mirada sigue atravesada por la historiografía decimonónica. Rafael Ramis, con la erudición del historiador y el rigor del filósofo, logra delimitar en los albores de la modernidad el origen de las tradiciones de la philosophia iuris y la philosophia iuris consultorum y su devenir conceptual hasta el siglo XIX. El nacimiento de la Filosofia del derecho derrumba viejos prejuicios historiográficos y traza nuevos caminos para la investigación. Sin duda, una obra que debe estar en toda Facultad de Derecho y de Filosofía; bibliografía recomendable en la asignatura de Filosofía del derecho; referencia obligada para todo filósofo y jurista. 